\title{
Estimation of Iron Content and Its Contribution in Iron-Fortified Food Products Consumed by School Children in Sri Lanka
}

\author{
D. Ruwani G. Perera ${ }^{D}{ }^{1}$, Dilantha Gunawardana ${ }^{D}{ }^{1}$ \\ Renuka Jayatissa $\mathbb{D}^{2},{ }^{2}$ and A. Buddhika G. Silva $\mathbb{D}^{2}$ \\ ${ }^{1}$ Department of Botany, University of Sri Jayewardenepura, Nugegoda 10250, Sri Lanka \\ ${ }^{2}$ Department of Nutrition, Medical Research Institute, Colombo 08 (00800), Sri Lanka \\ Correspondence should be addressed to A. Buddhika G. Silva; buddhika-gayani@mri.gov.lk
}

Received 16 January 2020; Accepted 31 March 2020; Published 26 November 2020

Academic Editor: Marina Carcea

Copyright $\odot 2020$ D. Ruwani G. Perera et al. This is an open access article distributed under the Creative Commons Attribution License, which permits unrestricted use, distribution, and reproduction in any medium, provided the original work is properly cited.

\begin{abstract}
Iron fortification is an effective strategy that can be implemented to ensure supply and intake of iron for the public at large. Even though iron-fortified foods are widely available in the Sri Lankan market, the quantification of iron in those foods is not under the regulations of the food authorities in Sri Lanka. Therefore, this study aims to quantify the concentration of iron in selected ironfortified foods available in the local market and determine their contribution to the recommended daily allowances (RDA) per serving. The iron content in most popular powdered milk, biscuits, and breakfast cereals among the children of 15-16 years in Horana Divisional Secretariat was analyzed using atomic absorption spectroscopy, and its contribution to RDA was calculated. The average iron values of iron-fortified milk powder (IFMP), iron-fortified biscuit (IFB), and iron-fortified breakfast cereals (IFBC) were found to be $18.08 \pm 9.53,7.88 \pm 0.07$, and $17.78 \pm 7.47 \mathrm{mg} / 100 \mathrm{~g}$, respectively. The average estimated daily intake (EDI) per serving of IFMP, IFB, and IFBC was $3.61 \pm 1.75,2.13 \pm 0.06$, and $5.60 \pm 1.45 \mathrm{mg}$, respectively. The highest contribution to the RDA can be obtained by a single serving of IFBC. Only less than half of the tested products have compatible iron levels with their labeled information. Iron-fortified foods which were studied have a high amount of iron, and they can make from 5\% to $35 \%$ contribution to RDAs in young children, adolescents, and adults even by a single serving.
\end{abstract}

\section{Introduction}

Fortification of food with micronutrients has been practiced for several years to restore the micronutrient loss during food processing and storage [1]. Iron fortification is a strategy implemented to ensure the proper supply and intake of iron among the general public [2, 3]. Food fortification means deliberately increasing the content of one or more essential nutrients in a food to improve the nutritional quality of food and to provide public health benefits $[4,5]$. It is often regarded as the most cost-effective and long-term approach to reduce iron deficiency $[6,7]$.

Enrichment of food with iron has been greatly assessed over the last few years in several regions of the world. Iron fortification of infant formulas showed a correlation with fall in the prevalence of anaemia in children aged under 5 years in the United States. In Venezuela, wheat and maize flour have been fortified with iron since 1993. A comparison among the prevalence of iron deficiency and pre- and postintervention of anaemia showed a significant reduction in the prevalence of these conditions in children. Fortification of milk with iron in Chile caused a rapid reduction in the prevalence of iron deficiency in infants and children $[2,7]$. Hallberg et al. [8] estimated that $25 \%$ of the total iron intake in Sweden and the United States comes from fortified iron. Likewise, iron fortification has caused a dramatic reduction in iron deficiency throughout the world [9].

Under the free market condition and with the advances in food technology, many types of processed foods are enriched with iron, whether required or not, to claim the superiority of the product [1]. This can be a cause of toxicological impact on specific groups of the population due to 
the excessive intake [10]. Sri Lankan staple diet is deficient in bioavailable iron [11], and iron fortification can be mainly implemented to fill up these inadequacies [1]. Even though several iron-enriched food products are available in the local market, the quantification of iron in those products is not practiced by food authorities in Sri Lanka. But, it is becoming a required factor because regulating the concentration levels of iron in processed foods which are purchased and consumed by all socioeconomic groups is preserving the nutritional balance and safety of the population at large.

Hence, this study was conducted to identify the comply of labeling on iron content of commonly consumed ironfortified food by school children aged 15-16years and to estimate the proportion of daily iron requirement received from these foods.

\section{Materials and Methods}

2.1. Study Population. School children aged 15-16 years were selected to identify the commonly consumed iron-fortified food considering the highest iron requirement and high prevalence of processed food consumption among them. According to the USDA guidelines, adolescents between 14 and 18 years of age require the highest RDA values [12]. The most important concern for the 15- to 16-year age group is to prepare for the General Ordinary Examination which is conducted to select the students for further education in Sri Lanka. The prevalence of iron deficiency in the school children of 10-18 years in Western Province, Sri Lanka, was $22.3 \%$ [13], which can directly affect their academic performance. Eight schools were randomly selected from the Horana Divisional Secretariat, Western province. Out of 1379 boys and 1645 girls aged 15-16years in the selected schools, 36 boys and 36 girls were randomly selected to introduce the food frequency questionnaire (FFQ) to identify the commonly consumed iron-fortified food items.

The Ethics Review Committee at the Faculty of Medicine, University of Sri Jayewardenepura, approved the study.

2.2. Iron-Fortified Commonly Consumed Food. Three types of commonly consumed iron-fortified food were identified from the FFQ. Those were milk powder, biscuits, and breakfast cereals. Six milk powder brands, two brands of biscuits, and three breakfast cereals were identified.

2.2.1. Collection of Samples. To perform the analysis, among six types of milk powder brands, five were labeled as ironfortified milk powder (IFMP)-A, B, C, D, and E and one was not labeled as iron fortified (non-IFMP)-F; among two types of biscuits, one was labeled as iron-fortified biscuit (IFB)-G and one not labeled as iron fortified (non-IFB)-H; and three types of breakfast cereals labeled as iron fortified breakfast cereals (IFBC)-I, J, and $\mathrm{K}$ were selected based on the popularity ratios among the study population. From each type of food, three samples from three different batches were purchased from the retail outlets and shops in the Horana area.
2.2.2. Determining Iron in Food Samples. A representative portion from each food sample was crushed to a homogenous fine powder by using a blender. Approximately $0.2500 \mathrm{~g}$ of the dry powdered sample in duplicate was digested using $3 \mathrm{~mL}$ of $69-71 \%$ (w/w) nitric acid and $1 \mathrm{~mL}$ of hydrogen peroxide (analytical grade) using the microwave digester. The clear digestion was transferred and made up to $25 \mathrm{~mL}$ with deionized water. The digested samples were analyzed in triplicate using a flame atomic absorption spectrophotometer (AAS) at a wavelength of $248.32 \mathrm{~nm}$. Calibration standard for iron was prepared using a stock solution of $1000 \mathrm{\mu gmL}^{-1}$ employing the serial dilution technique.

2.2.3. Quality Control. All glassware used in the assay was initially cleaned using detergent water and then with $5 \%$ nitric acid and finally rinsed several times with deionized water and oven dried. All plasticware was cleaned with detergent water, nitric acid, and deionized water, respectively, and allowed to dry in room temperature. Each batch of runs on the AAS was standardized by running a standard. The method validation was done by spiking of a known concentration of a standard solution with the known weight of the sample and then by estimating the recovery results.

2.2.4. Data Management and Statistical Analysis. Data were presented as the mean \pm standard deviation (SD). The significant differences between the mean iron content of collected samples were compared with the labeled iron value using the one-sample $t$-test. Comparison of average iron content among different brands was done orderly by oneway ANOVA in SPSS 23 software package. Statistical analysis was designed at $p<0.05$ and $95 \%$ confidence interval.

2.2.5. Estimated Daily Intake per Serving. The daily intake of an element is represented as a function of its concentration in the food sample and the amount of food that is consumed daily. The estimated daily intake (EDI) was calculated using the following equation $[14,15]$ :

$$
\mathrm{EDI}=C \times M \text {, }
$$

where $C$ is the mean content of iron in each food sample and $M$ is the assumed serving size. In this research, the serving size was assumed as the weight per serving defined by the manufacturers. The obtained iron values were then compared with the recommended daily allowance (RDA) for this age group (Table 1); the average daily intake level should be sufficient to meet the nutrient requirements of nearly all (97-98\%) healthy individuals in a particular life stage and a gender group. It is the standard value in assessing the adequacy of daily intake [17].

2.3. Contribution of Iron. The estimated contribution of each food type to the daily intake of iron was therefore calculated using the following equation [18]: 
TABLE 1: RDA for iron in boys and girls in the age group of 1516 years.

\begin{tabular}{|c|c|c|c|}
\hline \multirow[t]{2}{*}{ Gender } & \multirow{2}{*}{$\begin{array}{l}\text { RDA USDA (mg/d) [12] } \\
\text { 15-16 years age group }\end{array}$} & \multicolumn{2}{|c|}{$\begin{array}{l}\text { RDA Sri Lanka } \\
(\mathrm{mg} / \mathrm{d})[16]\end{array}$} \\
\hline & & 15 years & 16 years \\
\hline Girls & 15 & 36 & 39 \\
\hline Boys & 11 & 30 & 39 \\
\hline
\end{tabular}

$\mathrm{RDA}=$ recommended daily allowance and USDA $=$ United States Department of Agriculture.

contribution to RDA per serving $=\frac{\text { EDI per serving }}{\text { RDA }} \times 100 \%$.

\section{Results and Discussion}

Data were obtained from 36 boys and 36 girls randomly in eight schools in the Divisional Secretariat, Horana. Among them, 30 boys $(83.3 \%)$ and 33 girls $(91.7 \%)$ consumed milk powder. Only 10 boys (27.8\%) and 12 girls (33.3\%) consumed IFMPs (A, B, C, D, and E). Consumption of A, B, and $\mathrm{C}$ milk powders was $2.8 \%, 22.2 \%$, and $2.8 \%$, respectively, among boys, and they did not consume D and E IFMPs. B, $\mathrm{D}$, and $\mathrm{E}$ were the commonly consumed IFMPs among girls, and consumption levels were $27.8 \%, 2.8 \%$, and $2.8 \%$, respectively. The most commonly consumed non-IFMP was brand $\mathrm{F}$ with a consumption rate of $25.0 \%$ among boys and $11.1 \%$ among girls. Therefore, brand $\mathrm{F}$ was used as the control to perform the brandwise comparison among selected milk powders. $G$ was the most commonly consumed IFB, and $35.3 \%$ of boys and $25.0 \%$ of girls had consumed it. Similar consumption rates were reported for brand $\mathrm{H}$ among the selected population (32.4\% of boys and $25.0 \%$ of girls). Among the selected adolescents in the $15-16$ years age group, only $35.3 \%$ of boys and $25.0 \%$ of girls consumed IFBs. Out of the study population, $5.9 \%$ of boys and $28.6 \%$ of girls did not consume biscuits. Only 27 boys (75\%) and 20 girls (55.6\%) consumed IFBCs (I, J, and K). The most popular breakfast cereal was brand I with a consumption rate of $72.2 \%$ among boys and $52.8 \%$ among girls. $\mathrm{J}$ and $\mathrm{K}$ were the other selected IFBCs for the analysis, and they had considerably lower consumption levels among the children in the 15-16 years age category.

3.1. Milk Powder. According to Table 2, brand D contained a significantly higher amount of iron $(p<0.05)$ than the rest of the milk powders. The iron content in brand A was also significantly higher. No significant difference was observed among the average iron contents of other IFMPs. Brand $\mathrm{F}$ is the non-IFMP and had the lowest iron content compared to the rest. The iron levels of these six brands ranged from 6.28 to $33.72 \mathrm{mg} / 100 \mathrm{~g}$ (Table 2), while data obtained from similar studies reported values ranging from 7.1 to $16.1 \mathrm{mg} / 100 \mathrm{~g}$ [10]. The iron content obtained for milk powders in the present study was not compatible with the values reported by Lawal et al. [10]. However, the average iron content in each brand of powdered milk
TABLE 2: Average iron content of iron-fortified food varieties which are consumed by the adolescents (15-16 years) in the Divisional Secretariat, Horana.

\begin{tabular}{lcc}
\hline $\begin{array}{l}\text { Type } \\
\text { Milk powder }\end{array}$ & $\begin{array}{c}\text { Labeled iron content, } \\
\mathrm{mg} / 100 \mathrm{~g}\end{array}$ & $\begin{array}{c}\text { Tested iron content, } \\
\mathrm{mg} / 100 \mathrm{~g}\end{array}$ \\
\hline Brand A & 20 & $19.8 \pm 2.08$ \\
\hline Brand B & 11.25 & $10.78 \pm 3.42$ \\
\hline Brand C & 18.9 & $9.27 \pm 3.39$ \\
\hline Brand D & 31 & $33.72 \pm 1.37$ \\
\hline Brand E & 14.8 & $16.82 \pm 6.47$ \\
\hline Brand F & 0.37 & $6.28 \pm 0.38$ \\
\hline Biscuits & & $7.88 \pm 0.22$ \\
\hline Brand G & 4.7 & $1.12 \pm 0.07$ \\
\hline Brand H & 1.01 & $10.42 \pm 1.48$ \\
\hline Breakfast cereals & & $25.19 \pm 5.39$ \\
\hline Brand I & 3 & $17.73 \pm 5.23$ \\
\hline Brand J & 14.07 & \\
\hline Brand K & 14.07 & \\
\hline
\end{tabular}

which was selected for the present study was significantly higher than the values reported by Semaghiul et al. [19] $(2.173 \mathrm{mg} / 100 \mathrm{~g})$, Salah et al. [20] (2.041 mg/100 g), Zhao et al. [21] $(5.6 \mathrm{mg} / 100 \mathrm{~g})$, and Perween et al. [22] $(0.433 \mathrm{mg} / 100 \mathrm{~g})$. Only the tested iron contents of brands $\mathrm{A}, \mathrm{B}$, and $\mathrm{E}$ were compatible with the labeled iron contents. The labeled iron content of $\mathrm{C}$ was twice the value of what was obtained from the study, and $\mathrm{D}$ had a lower labeled iron level than the value obtained from the study. Milk powders are usually fortified by market-driven fortification [1]. A, B, and C were fortified with ferric pyrophosphate, and the rest have not specified the added compound for the fortification.

3.2. Biscuits. Brand $G$ is enriched with iron and had a significantly higher iron content $(p<0.05)$ than brand $\mathrm{H}$ (Table 2). Meanwhile, brands $\mathrm{G}$ and $\mathrm{H}$ reported higher iron contents than the labeled values. $G$ is a cracker-type biscuit, and its iron content is compatible with the iron content in crackers which had been reported by similar studies [23]. Some studies have reported a higher iron content in sweet biscuits such as chocolate, coconut, malted milk, chocolate wafer, and strawberry wafer biscuits compared to brand $\mathrm{H}$ [23]. Higher iron levels were found to be present in IFBs compared to the values reported by Bivan et al. [24] and Debels et al. [25]. Targeted fortification is the implemented strategy to fortify the IFBs [1], and the added compound for the fortification of $G$ was not specified by the manufacturer.

3.3. Breakfast Cereals. All breakfast cereal varieties consumed by the study population were enriched with iron and fortified using the market-driven fortification method [1]. Ferric pyrophosphate is the added compound in brand I for the fortification, and the rest do not specify the 
exact iron compound which is added. The iron levels of these three types of IFBCs ranged from 10.42 to $25.19 \mathrm{mg}$ / $100 \mathrm{~g}$ (Table 2), while data obtained from similar studies reported values ranging from 549 to $737 \mathrm{mg} / 100 \mathrm{~g}$ [26]. A similar study reported the iron content in breakfast cereals to be $29.3 \pm 12.9 \mathrm{mg}$ which is compatible with the present study [27]. Higher iron contents were found to be present in the selected breakfast cereals compared to the values reported by Bruggraber et al. [28], FSA [29], and McCance and Widdowson [30]. The level of iron was significantly higher in brand J compared to brands I and $\mathrm{K}$. Only the tested iron value of brand $\mathrm{K}$ was compatible with its labeled value.

The total amount of iron found to be in each selected iron-fortified food product does not depend only on the added compound to enrich iron. Meanwhile, the other ingredients used to produce each product also have contributed to the total iron level. Based on the labeled information, the ingredients added by the manufacturer for the production of each food product are given in Table 3 .

According to Table 3, some of the products containing whole milk, cocoa powder $(13.86 \mathrm{mg} / 100 \mathrm{~g})$ [31], malted barley (4.71 mg/100 g) [31], wheat flour (3.71 mg/100 g) [31], and corn flour $(2.48 \mathrm{mg} / 100 \mathrm{~g})$ [31] are contributing a considerable iron amount to the total iron content of each food, whereas some products do not contain such ingredients with considerable amount of iron.

3.4. Milk Powder. According to Table 4, the highest iron content per serving can be obtained by brand D $(6.74 \pm 0.26 \mathrm{mg})$. The mean estimated iron intake that can be obtained through these five brands of IFMPs was $3.61 \pm 1.75 \mathrm{mg}$ per serving (Table 4 ). Based on the USDA guidelines, this contributes to $32.82 \%$ and $24.07 \%$ of the daily requirement of boys and girls in the age group of 1516 years, respectively. But, based on the Sri Lankan guidelines, this estimated daily intake per serving contributes to $10.03 \%, 9.26 \%, 12.03 \%$, and $9.26 \%$ of the daily requirement of 15-year-old girls, 16-year-old girls, 15-year-old boys, and 16-year-old boys, respectively. Lowest estimated daily intake per serving can be obtained by brand F. Based on the Sri Lankan guidelines, it only contributes to $4.53 \%, 4.18 \%$, $5.43 \%$, and $4.18 \%$ of the daily requirement of 15 -year-old girls, 16-year-old girls, 15-year-old boys, and 16-year-old boys, respectively.

3.5. Biscuits. A mean iron content of $2.13 \pm 0.06 \mathrm{mg}$ per serving can be obtained from brand G (Table 4). Based on the USDA guidelines, it contributes to $19.36 \%$ of boys' and $14.20 \%$ of girls' daily iron requirements. Meanwhile, based on the Sri Lankan guidelines, it only contributes to the daily requirement of $5.92 \%, 5.46 \%, 7.10 \%$, and $5.46 \%$ of 15 -yearold girls, 16-year-old girls, 15-year-old boys, and 16-yearold boys, respectively. As brand $\mathrm{H}$ is a noniron-fortified biscuit, only $0.26 \pm 0.01 \mathrm{mg}$ of iron can be obtained per serving (Table 4). According to the USDA guidelines, it contributes to $2.36 \%$ and $1.73 \%$ of the RDAs of boys and girls of 15-16 years. Moreover, based on Sri Lankan guidelines, it only contributes to the daily iron requirements of $0.72 \%, 0.67 \%, 0.87 \%$, and $0.67 \%$ of 15 -year-old girls, 16-year-old girls, 15-year-old boys, and 16-year-old boys, respectively.

3.6. Breakfast Cereals. Highest iron content per serving, which is $6.80 \pm 1.39 \mathrm{mg}$, can be obtained by brand J (Table 4). A mean iron content of $5.60 \pm 1.45 \mathrm{mg}$ per serving can be obtained from the selected brands of breakfast cereals (Table 4). Based on the USDA guidelines, it contributes to $50.91 \%$ and $37.33 \%$ of the recommended daily requirement of boys and girls in the 15- to 16-year age category. According to Sri Lankan guidelines, it only contributes to the daily requirement of $15.56 \%, 14.36 \%, 18.67 \%$, and $14.36 \%$ of 15 -year-old girls, 16-year-old girls, 15 -year-old boys, and 16-year-old boys, respectively.

A considerable amount of iron can be obtained through these iron-fortified foods even by a single serving. The selected powdered milk, biscuits, and breakfast cereals had been regularly purchased and consumed by all family members in all socioeconomic classes. Generally, it is difficult to set maximum limits on the permitted levels of fortification in such foods because maximum iron intake varies with age and gender. However, the legal minimum and maximum levels should be applied to the amount of both naturally occurring and fortified micronutrients present in the food. Iron is considered as a trace element, and naturally occurring iron content is likely to be negligible; thus, the legal minimum and maximum levels approximate to the range of permitted micronutrient addition. However, the maximum level can be referred to as the tolerable upper intake for each age category [1]. This value for 6-18 year olds and 19-70 year olds is $40 \mathrm{mg} / \mathrm{day}$ and $45 \mathrm{mg} /$ day, respectively, for both genders. According to the FAO/WHO [32], the maximum limit for iron in food is $42.5 \mathrm{mg} / 100 \mathrm{~g}$. The results obtained in the present study are lower than the recommended concentration of iron by the FAO/WHO [32] and tolerable upper intake levels.

The iron requirement of different stages of life varies widely, and the RDA varies with the age categories and gender. RDA for young children and adolescents vary from 16 to $39 \mathrm{mg}$ in both genders. An adult Sri Lankan male requires $22 \mathrm{mg}$ per day, and adult female requires $20-33 \mathrm{mg}$ of iron to satisfy the daily iron requirement. During pregnancy and lactation, $33 \mathrm{mg}$ of iron is required per day. Highest iron requirement per day can be found among adolescents in the age group of 16-18 years. Based on the adults' daily iron requirement, nonmenstruating females of $30-59.9$ years and above 60 years have the lowest requirement which is $20 \mathrm{mg} /$ day [16]. The selected IFMPs, IFBs, and IFBCs were not categorized for specific age groups. Therefore, these products were used by the general public without awareness of their daily iron requirement. Moreover, it is required to clarify the estimated daily intake per serving and its contribution to the RDA of the whole population. The percentage contributions to the RDA per serving of the selected IFMP, IFB, and IFBC for all age categories are presented in Table 5. 
TABLE 3: Added ingredients to produce each food product by the manufacturer (based on the labeled information).

\begin{tabular}{|c|c|}
\hline Type & Ingredient (as mentioned on the label by the manufacturer) \\
\hline \multicolumn{2}{|l|}{ Milk powder } \\
\hline Brand A & Milk solids, malt extract, sugar, cocoa powder, vegetable oil, calcium phosphate, vitamins, ferric pyrophosphate, vamillin \\
\hline Brand B & $\begin{array}{c}\text { Milk solids, malt extract, palm oil, calcium carbonate, soya lecithin, iodized salt, sodium carbonate, vitamins, magnesium } \\
\text { phosphate, colour caramel (INS 150a), ferric pyrophosphate }\end{array}$ \\
\hline Brand $\mathrm{C}$ & $\begin{array}{c}\text { Milk solids, corn solids, calcium bicarbonate, potassium bicarbonate, emulsifier (INS 412), sodium bicarbonate, ferric } \\
\text { pyrophosphate, vitamins }\end{array}$ \\
\hline Brand D & $\begin{array}{c}\text { Milk solids, malted barley (extracted solids), protein isolates, minerals, acidity regulator (INS } 501 \text { (ii)), salt, vitamins, } \\
\text { edible fiber (INS 412) }\end{array}$ \\
\hline Brai & Whole milk $(0.03 \mathrm{mg} / 100 \mathrm{~g})$, vitamins, sugar, minerals \\
\hline Brand F & Whole milk powder \\
\hline \multicolumn{2}{|l|}{ Biscuits } \\
\hline Brand G & Wheat flour, vegetable oil, leavening agents (E 500 ii), soya lecithin, malt extract, vitamins, minerals \\
\hline Brand $\mathrm{H}$ & $\begin{array}{l}\text { Wheat flour, sugar, vegetable oil, corn flour, leavening agents (E } 500 \mathrm{ii}, \mathrm{E} 503 \mathrm{ii} \text { ), cocoa powder, salt, soya lecithin, nature } \\
\text { identical (chocolate flavor), permitted colour (E 110, E 122, E 133) }\end{array}$ \\
\hline \multicolumn{2}{|l|}{$\begin{array}{l}\text { Breakfast } \\
\text { cereals }\end{array}$} \\
\hline Brand I & Wheat, soya, rice, green Gram, calcium carbonate, vitamin C, vitamin B12, ferric pyrophosphate \\
\hline Brar & $\begin{array}{c}\text { Wheat solids, wheat flour, sugar, cocoa solids, edible vegetable oil, malt extract, minerals, iodized salt, colour (INS 150d), } \\
\text { vitamins }\end{array}$ \\
\hline rand $\mathrm{K}$ & Whole wheat flour, multigrain flour, whole corn flour, barley flour, oats flour, honey, minerals, vitamins \\
\hline
\end{tabular}

TABLE 4: Estimated daily intake of iron per serving of each food item and their contribution to RDA.

\begin{tabular}{|c|c|c|c|c|c|c|c|c|}
\hline & \multicolumn{8}{|c|}{ Contribution to RDA \% } \\
\hline & \multirow[b]{2}{*}{ Serving size $(\mathrm{g})$} & \multirow[b]{2}{*}{ EDI per serving $(\mathrm{mg})$} & \multicolumn{2}{|c|}{ Based on USDA guidelines } & \multicolumn{4}{|c|}{ Based on SL guidelines } \\
\hline & & & $\begin{array}{c}\text { Girls } \\
\text { 15-16 years }\end{array}$ & $\begin{array}{c}\text { Boys } \\
15-16 \text { years }\end{array}$ & $\begin{array}{c}\text { Girls } \\
15 \text { years }\end{array}$ & $\begin{array}{c}\text { Girls } \\
16 \text { years }\end{array}$ & $\begin{array}{c}\text { Boys } \\
15 \text { years }\end{array}$ & $\begin{array}{c}\text { Boys } \\
16 \text { years }\end{array}$ \\
\hline \multicolumn{9}{|c|}{ Iron-fortified milk powder } \\
\hline Brand $\mathrm{A}$ & 15.0 & $2.97 \pm 0.30$ & 19.80 & 27.00 & 8.25 & 7.62 & 9.90 & 7.62 \\
\hline Brand B & 25.0 & $2.69 \pm 0.82$ & 17.93 & 24.45 & 7.47 & 6.90 & 8.97 & 6.90 \\
\hline Brand $\mathrm{C}$ & 28.0 & $2.60 \pm 0.91$ & 17.33 & 23.64 & 7.22 & 6.67 & 8.67 & 6.67 \\
\hline Brand D & 20.0 & $6.74 \pm 0.26$ & 44.93 & 61.27 & 18.72 & 17.28 & 22.47 & 17.28 \\
\hline Brand E & 18.0 & $3.03 \pm 1.11$ & 20.20 & 27.55 & 8.42 & 7.77 & 10.10 & 7.77 \\
\hline Mean & 21.2 & $3.61 \pm 1.75$ & 24.07 & 32.82 & 10.03 & 9.26 & 12.03 & 9.26 \\
\hline \multicolumn{9}{|c|}{ Noniron-fortified milk powder } \\
\hline Brand $\mathrm{F}$ & 26.0 & $1.63 \pm 0.09$ & 10.87 & 14.82 & 4.53 & 4.18 & 5.43 & 4.18 \\
\hline \multicolumn{9}{|c|}{ Iron-fortified biscuit } \\
\hline Brand G & 27.0 & $2.13 \pm 0.06$ & 14.20 & 19.36 & 5.92 & 5.46 & 7.10 & 5.46 \\
\hline \multicolumn{9}{|c|}{ Noniron-fortified biscuit } \\
\hline Brand $\mathrm{H}$ & 23.0 & $0.26 \pm 0.01$ & 1.73 & 2.36 & 0.72 & 0.67 & 0.87 & 0.67 \\
\hline \multicolumn{9}{|c|}{ Iron-fortified breakfast cereal } \\
\hline Brand I & 50.0 & $5.21 \pm 0.71$ & 34.73 & 47.36 & 14.47 & 13.36 & 17.37 & 13.36 \\
\hline Brand J & 27.0 & $6.80 \pm 1.39$ & 45.33 & 61.82 & 18.89 & 17.44 & 22.67 & 17.44 \\
\hline Brand $\mathrm{K}$ & 27.0 & $4.79 \pm 1.35$ & 31.93 & 43.55 & 13.31 & 12.28 & 15.97 & 12.28 \\
\hline Mean & 34.7 & $5.60 \pm 1.45$ & 37.33 & 50.91 & 15.56 & 14.36 & 18.67 & 14.36 \\
\hline
\end{tabular}

$\mathrm{EDI}=$ estimated daily intake, $\mathrm{RDA}=$ recommended daily allowance, $\mathrm{USDA}=$ United State Department of Agriculture, and SL = Sri Lanka.

The highest iron content per serving can be obtained by iron-fortified breakfast cereals $(5.60 \mathrm{mg})$. Based on Table 5, among the young children and adolescents, contribution to the RDA per serving by IFMPs ranged from $9.26 \%$ to $22.56 \%$ in boys and $9.26 \%$ to $22.56 \%$ in girls. The contribution to RDA varied from $5.46 \%$ to $13.31 \%$ in boys and $5.46 \%$ to
$13.31 \%$ in girls by a single serving of IFB. Similarly, the contribution from IFBC ranged from $14.36 \%$ to $35.0 \%$ in boys and $14.36 \%$ to $35.0 \%$ in girls in the age group of 6-18 years. Highest and lowest percentage contribution to RDA per serving of IFMP, IFB, and IFBC were found to be in children and adolescents in the age groups 6-9 and 
TABLE 5: Average estimated daily intake of iron per serving of IFMPs, IFBs, and IFBCs and their contribution to RDA.

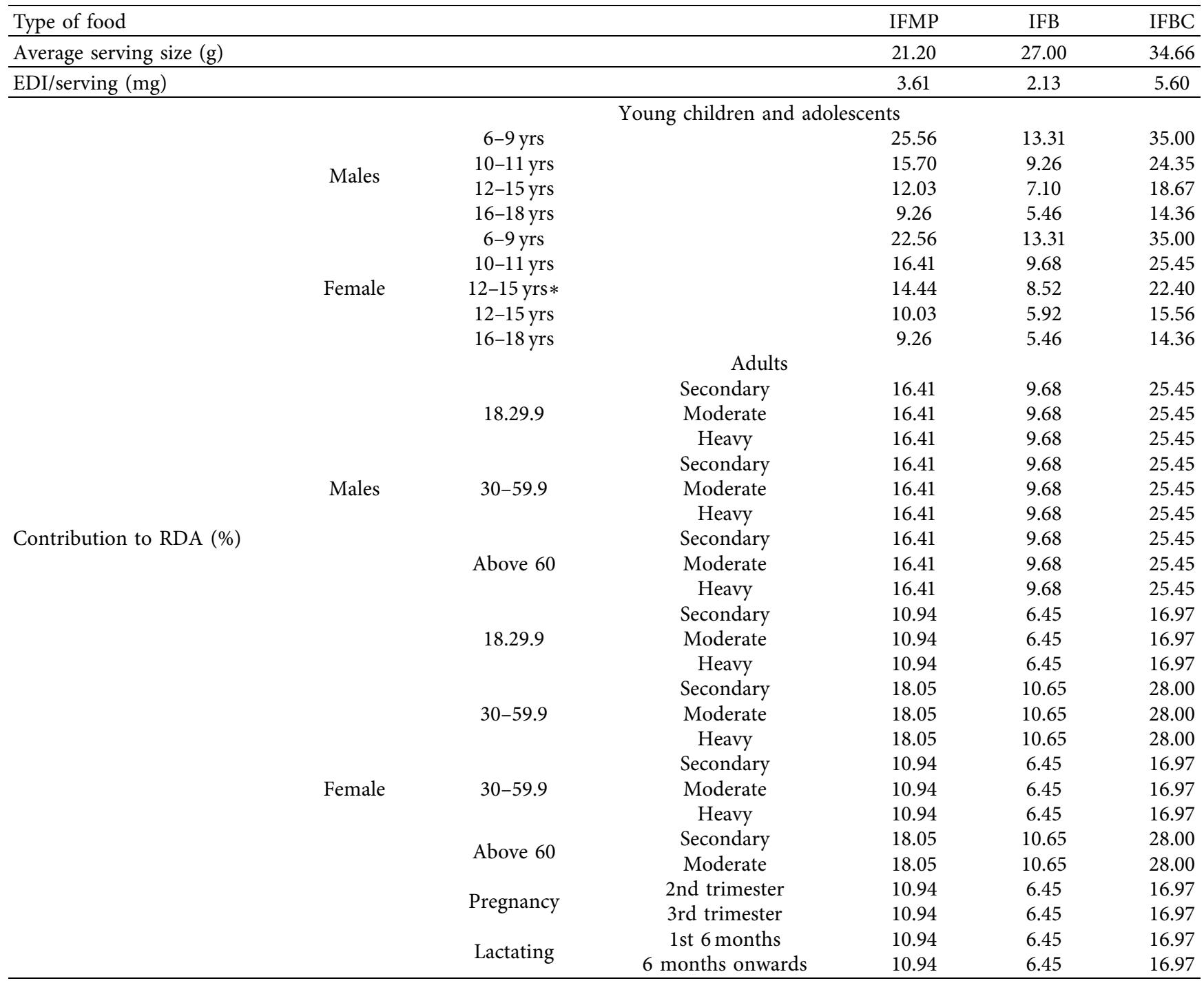

16-18 years, respectively. According to defined values of RDA for Sri Lankans, an adult male requires $22 \mathrm{mg}$ of dietary iron to satisfy his RDA [16]. IFBC provides the highest contribution $(25.45 \%)$ to this, while the lowest contribution (9.68\%) was from a single serving of IFB. Similarly, highest iron contribution to RDA per serving was provided by IFBC in individuals aged 18-29.9 years, nonmenstruating women of 30-59.9 years, adults aged 30-59.9 years and above 60 years, and pregnant and lactating adult females. The lowest contribution was given by a single serving of IFB in all of the abovementioned age categories. The percentage contributions to RDA per serving of IFMP, IFB, and IFBC ranged from $10.94 \%$ to $18.05 \%, 6.45 \%$ to $10.65 \%$, and $16.97 \%$ to $28.0 \%$, respectively, in females aged $18-60$ years and above.

If an individual of young children and adolescents consumes IFMPs as the only source of iron, 4 times, 6 times, 8 times, and 11 times of servings must be consumed per day by boys and girls of 6-9 years, 10-11 years, 12-15 years, and 16-18 years to satisfy their RDAs. If the IFB is the only source of iron, they have to consume from 8 times to 18 times of servings per day. If these children and adolescents choose the IFBCs as the only source of iron, boys and girls of 6-9 years, $10-11$ years, $12-15$ years, and $16-18$ years must consume 3 times, 4 times, 5 times, and 7 times of serving, respectively, to fulfill their daily iron requirements. Males in the 18 years to above 60 years age range must consume 6 times, 10 times, and 4 times of servings of IFMPs, IFB, and IFBCs per day to achieve their RDAs. Females 18-29.9 years old and 30-59.9 years old and pregnancy and lactating women require high levels of iron than others [16], and if they selected these IFMPs, IFBs, and IFBCs as their only source of iron, they need to consume 9 times, 15 times, and 6 times of servings of each food category, respectively. Nonmenstruating females 30-59.9 years old and adult females in above 60 age categories require 6 times, 9 times, and 4 times of servings of IFMPs, IFBs, and IFBCs, respectively, to satisfy their daily iron requirements.

However, the same serving size of the fortified food is common to all members of the family, and they may 
consume more than one serving per day. Therefore, an unnecessary amount of iron may be delivered to the children as well. As dietary iron can be absorbed from different food sources in varied quantities and as Sri Lankan staple food also contains a considerable amount of iron [33], this might lead to an excessive intake of iron for those age groups. Excessive intake may cause toxicological effects such as iron poisoning which can occur if children accidentally consume adult doses of iron [13]. Even though an excessive intake occurs, all of the dietary iron consumed may not be absorbed by the body due to the individual's iron status and requirement [34, 35], nature of the source of iron [36], total iron content within the meal [36], amount of iron released, and other associated constituents of the meal [37].

\section{Conclusions}

Only less than half of the tested products were compatible with their labeled information. These iron-fortified food products have high iron content and can provide significant contribution towards the daily iron requirements of children aged 15-16 years. Based on the single serving contribution, IFMPs and IFBCs were considered as the best sources of iron while they provide significant contribution (from 5\% to $35 \%$ ) to the RDA in young children, adolescents, and adults even by a single serving.

\section{Data Availability}

The data used to support the findings of this study are available from the corresponding author upon request.

\section{Conflicts of Interest}

The authors declare that they have no conflicts of interest.

\section{Acknowledgments}

The study was made possible through the support of the Department of Nutrition, especially the laboratory staff, Medical Research Institute, Sri Lanka, and the Department of Botany and Instrument Centre at University of Sri Jayewardenepura, Sri Lanka.

\section{References}

[1] Ministry of Healthcare and Nutrition, Sri Lanka, Policy Guidelines for Fortification of Food in Sri Lanka, Ministry of Healthcare and Nutrition, Sri Lanka, Geneva, Switzerland, 2008, http://www.health.gov.lk/enWeb/publication/Policy\% 20Guidlines\%20for\%20Fortification\%20of\%20Food\%20in\% 20Sri\%20Lanka\%203.pdf.

[2] WHO/FAO, Guidelines on Food Fortification with Micronutrients, L. Allen and B. de Benoist, Eds., World Health Organization, Geneva, Switzerland, 2006, http://whqlibdoc. who.int/publications/2006/9241594012_eng.pdf?ua=1\&ua=1.

[3] P. Niedzielski, M. Zielinska-Dawidziak, L. Kozak et al., "Determination of iron species in samples of iron-fortified food," Food Analytical Methods, vol. 7, no. 10, pp. 2023-2032, 2014.
[4] FAO/WHO, Codex Alimentarius, World Health Organization, Geneva, Switzerland, 2nd edition, 1994.

[5] FAO, Food Fortification: Technology and Quality Control, FAO Food and Nutrition paper, Rome, Italy, 1995.

[6] R. F. Hurrell, "Preventing iron deficiency through food fortification," Nutrition Reviews, vol. 55, no. 6, pp. 210-222, 1997.

[7] S. K. Jyvakopri, H. Martinez, A. Pineda, and S. Pizarro, "Iron nutrition in school children of western Mexico: the effect of iron fortification," Ecology of Food and Nutrition, vol. 45, pp. 431-447, 2006.

[8] L. Hallberg and L. Rossander-Hultén, "Iron requirements in menstruating women," The American Journal of Clinical Nutrition, vol. 54, no. 6, pp. 1047-1058, 1991.

[9] S. Denic and M. M. Agarwal, "Nutritional iron deficiency: an evolutionary perspective," Nutrition, vol. 23, no. 7-8, pp. 603-614, 2007.

[10] N. S. Lawal, N. Tajuddeen, and B. B. Garba, "Assessment of some mineral elements in different brands of powdered milk sold in Samaru Zaria, Nigeria," International Food Research Journal, vol. 22, no. 6, pp. 2634-2636, 2015.

[11] G. Chathuranga, T. Balasuriya, and R. Perera, Anaemia Among Female Undergraduates Residing in the Hostels of University of Sri Jayewardenepura, Ministry of Health, Nutrition and Welfare, Sri Lanka, India, 2014.

[12] United States Department of Health and Human Services, Iron-fact Sheet for Health Professionals, National Institute of Health U.S., Department of Health and Human Services, Washington, DC, USA, 2019, https://ods.od.nih.gov/ factsheets/Iron-HealthProfessional/\#en5.

[13] Medical Research Institute of the Health Sciences, Survey Report-Assessment of Anaemia Status in Sri Lanak, Medical Research Institute of the Health Sciences, Ministry of Health, Nutrition and Welfare, Sri Lanka, India, 2001.

[14] T. Pedron, F. R. Segura, F. F. da Silva, A. L. de Souza, H. F. Maltez, and B. L. Batista, "Essential and non-essential elements in Brazilian infant food and other rice-based products frequently consumed by children and celiac population," Journal of Food Composition and Analysis, vol. 49, pp. 78-86, 2016.

[15] E. Pinto, A. Almeida, and I. M. P. L. V. O. Ferreira, "Essential and non-essential/toxic elements in rice available in the Portuguese and Spanish markets," Journal of Food Composition and Analysis, vol. 48, pp. 81-87, 2016.

[16] Medical Research Institute, Recommended Daily Allowances for Sri Lankans, Department of Nutrition, Medical Research Institute, Sri Lanka, India, 2007.

[17] E. Damastuti, W. Y. N. Syahfitri, M. Santoso, and D. D. Lestiani, "Assessment of trace element daily intake based on consumption rate of foodstuffs in Bandung City," Atom Indonesia, vol. 38, no. 1, pp. 29-34, 2012.

[18] W. Y. N. Syahfitri, E. Damastuti, N. Adventini et al., "Essential minerals of rice in West java Indonesia and its daily intake estimation," Atom Indonesia, vol. 44, no. 3, pp. 155-163, 2018.

[19] B. Semaghiul, D. Simona, S. Gabriela, and S. Alina, "Determination of major and minor elements in milk through ICPAES," Environmental Engineering and Management Journal, vol. 7, no. 6, pp. 805-808, 2008.

[20] F. A. A. E. Salah, I. A. Esmat, and A. B. Mohamed, "Heavy metals residues and trace elements in milk powder marketed in Dakahlia Governorate," International Food Research Journal, vol. 20, no. 4, pp. 1807-1812, 2013.

[21] G. Zhao and B. Li, IFIP International Federation for Information Processing, D. Li and Z. Chunjiang, Eds., Springer, Boston, MA, USA, 2009. 
[22] R. Perween, M. Mumtaz, Q. Haque, and T. Mehmood, "Nutritional values in aspects of essential and non-essential elements in variety of milk samples by AAS and FES," Journal of the Chemical Society of Pakistan, vol. 33, no. 3, pp. 313-316, 2011.

[23] M. E. A. d. Passos, C. F. F. Moreira, M. T. B. Pacheco, I. Takase, M. L. M. Lopes, and V. L. Valente-Mesquita, "Proximate and mineral composition of industrialized biscuits," Food Science and Technology, vol. 33, no. 2, pp. 323-331, 2013.

[24] S. K. Bivan and J. Eke-Ejiofor, "Chemical and mineral analysis of biscuits and cakes produced from acha, soybean and groundnut flour blends," Food Science and Nutrition Technology, vol. 33, pp. 2574-2701, 2019.

[25] D. Nanyen, I. B. Dooshima, A. Julius, and I. Benbella, "Nutritional composition, physical and sensory properties of cookies from wheat, acha and mung bean composite flours," International Journal of Nutrition and Food Sciences, vol. 5, no. 6, pp. 401-406, 2016.

[26] J. Eke-Ejiofor and E. A. Beleya, "The-Compositional-andMineral-Content-of-Granola-Breakfast-cereal-Produced-

from different-locally-available-cereal-grains," European Journal of Food Science and Technology, vol. 33, pp. 18-26, 2016.

[27] A. Winiarska-Mieczan, E. Kowalczuk-Vasilev, K. Kwiatkowska et al., "Dietary intake and content of $\mathrm{Cu}, \mathrm{Mn}, \mathrm{Fe}$, and $\mathrm{Zn}$ in selected cereal products marketed in Poland," Biological Trace Element Research, vol. 187, no. 2, pp. 568-578, 2019.

[28] S. F. A. Bruggraber, T. P. E. Chapman, C. W. Thane, A. Olson, R. Jugdaohsingh, and J. J. Powell, "A re-analysis of the iron content of plant-based foods in the United Kingdom," British Journal of Nutrition, vol. 108, no. 12, pp. 2221-2228, 2012.

[29] Food Standards Agency, McCance and Widdowson's the Composition of Foods, Royal Society of Chemistry, Cambridge, UK, 6th edition, 2002.

[30] R. McCance and E. Widdowson, The Chemical Composition of Foods, His Majesty's Stationery Office, London, UK, 1940.

[31] USDA national nutrient database, https://ndb.nal.usda.gov/ $\mathrm{ndb} /$.

[32] FAO/WHO, Codex Alimentarius Commission. Food Additives and Contaminants, Joint FAO/WHO Food Standards Programme, ALINORM, London, UK, 2001.

[33] D. R. G. Perera, D. Gunawardana, R. Jayatissa, and A. B. G. Silva, "Iron content of some popular cooked foods consumed by the rural school children in Sri Lanka," Journal of Food Quality, vol. 2019, 2019.

[34] J. D. Cook, "Adaptation in iron metabolism," The American Journal of Clinical Nutrition, vol. 51, no. 2, pp. 301-308, 1990.

[35] T. H. Bothwell, R. W. Charlton, J. D. Cook, and C. A. Finch, Iron Absorption and Iron Metabolism in Man, Blackwell Scientific Publications, London, UK, 1989.

[36] H. C. Schonfeldt, "Hall of 8th international food data conference," Journal of Food Composition and Analysis, vol. 24, pp. 469-756, 2011.

[37] P. E. Adams, "Determining iron content in foods by spectrophotometry," Journal of Chemical Education, vol. 72, no. 7, p. $649,1995$. 